\title{
Estudo comparativo da osteointegração de enxertos ósseos irradiados e não irradiados utilizados em pacientes com revisão de artroplastia do quadril ${ }^{*}$
}

\section{Comparative Study of the Osteointegration of Irradiated and Non-irradiated Bone Grafts Used in Patients with Revision Hip Arthroplasty}

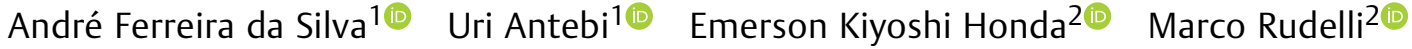 \\ Rodrigo Pereira Guimarães ${ }^{2}$
}

\footnotetext{
${ }^{1}$ Banco de Tecidos Musculoesquelético, Irmandade da Santa Casa de Misericórdia de São Paulo, São Paulo, SP, Brasil

2 Departamento de Ortopedia e Traumatologia, Santa Casa de São Paulo, Faculdade de Ciências Médicas da Santa Casa de São Paulo, São Paulo, SP, Brasil
}

Rev Bras Ortop 2019;54:477-482.
Endereço para correspondência André Ferreira da Silva, MD, Rua Nossa Senhora do Desterro, 05, Terra Preta, Mairiporã, São Paulo, SP, 07600-000, Brasil (e-mail: ferreiradasilva_andre@yahoo.com.br).

\section{Resumo \\ Palavras-chave \\ - osteointegração \\ - banco de tecidos \\ - enxertos ósseos \\ - artroplastia}

Objetivo Avaliar e comparar a osteointegração dos enxertos ósseos congelados irradiados e não irradiados utilizados em 21 pacientes submetidos a revisão de prótese do quadril pela técnica Exeter.

Métodos Foi realizado estudo retrospectivo de 21 pacientes submetidos a revisão de artroplastia do quadril pela técnica Exeter com utilização de tecidos ósseos tratados ou não com radiação gama no período entre 2013 e 2014. Dividimos os pacientes em dois grupos, de acordo com o uso do enxerto tratado ou não com radiação ionizante (raios gama), que foram, portanto, classificados como: grupo irradiado e não irradiado. Os resultados da osteointegração por análise radiográfica destes enxertos foram comparados no pós-cirúrgico de 6 e 12 meses.

Resultados Quando comparamos a osteointegração dos enxertos no pós-cirúrgico de $6 \mathrm{e}$ 12 meses de todos os pacientes, notamos que houve diferença significativa entre as avaliações radiográficas neste período $(p=0,031)$. Dos pacientes estudados, 7 pertenciam

\footnotetext{
Trabalho desenvolvido no Hospital Central da Irmandade da Santa Casa de Misericórdia de São Paulo, São Paulo, SP, Brasil.

(D) André Ferreira da Silva's ORCID is https://orcid.org/0000-0002-83842208.

(D) Uri Antebi's ORCID is https://orcid.org/0000-0002-3185-7766.

(1) Emerson Kiyoshi Honda's ORCID is https://orcid.org/0000-00019448-2335.

(D) Marco Rudelli's ORCID is https://orcid.org/0000-0003-1106-0706.

(D) Rodrigo Pereira Guimarães's ORCID is https://orcid.org/0000-00020564-4660.
}

Recebido

05 de Julho de 2018

Aceito

12 de Março de 2019
DOI https://doi.org/

10.1055/s-0039-1694715. ISSN 0102-3616.

\section{Introdução}

No Brasil, os tecidos ósseos homólogos humanos são os mais transplantados em comparação com outros transplantes, tais como os de pele, de córnea e de medula óssea. Eles são utilizados nas reconstruções ortopédicas e odontológicas, e sua demanda cresceu na última década. ${ }^{1}$

Os tecidos ósseos autólogos são considerados o "padrãoouro" quando utilizados nas cirurgias de reconstrução. Isso se

Copyright $\odot 2019$ by Sociedade Brasileira License terms de Ortopedia e Traumatologia. Published by Thieme Revnter Publicações Ltda, Rio de Janeiro, Brazil 
ao grupo irradiado, e 14, ao grupo não irradiado. Não foram observadas diferenças estatisticamente significativas $(p=0,804)$ quando a osteointegração entre os grupos irradiados e não irradiados foi comparada.

Conclusão Não houve diferença significativa no uso de enxerto irradiado e não irradiado nas revisões de artroplastias do quadril pela técnica Exeter.

\section{Abstract}

\section{Keywords \\ - osteointegration \\ - tissue bank \\ - bone grafts \\ - arthroplasty}

Objective To evaluate and compare the osteointegration of irradiated and nonirradiated frozen bone grafts used in 21 patients undergoing revision hip arthroplasty using the Exeter technique.

Methods A retrospective study of 21 patients undergoing revision hip arthroplasty with the Exeter technique using bone tissues treated or not with gamma radiation between 2013 and 2014. The patients were divided into two groups, according to the use of grafts treated or not with ionizing radiation (gamma rays); as such, those groups were classified as: the irradiated and non-irradiated groups. The osseointegration results determined by radiographic analysis of these grafts were compared in the postoperative period of 6 and 12 months.

Results Comparing the graft osseointegration in all patients at 6 and 12 months postoperatively, we noticed a significant difference in the radiographic evaluations in this period $(p=0.031$ ). Out of the patients studied, 7 belonged to the irradiated group and 14 , to the non-irradiated group. No statistically significant differences were observed ( $p=0.804$ ) when we compared the osteointegration between the irradiated and non-irradiated groups.

Conclusion There was no significant difference in the use of irradiated or nonirradiated grafts in the revision hip arthroplasties by the Exeter technique. deve às suas propriedades osteogênicas, osteoindutoras e osteocondutoras, e por não causarem reação imunológica. Porém, os tecidos ósseos homólogos têm vantagens quando comparados aos autólogos, tais como a redução da morbidade, por evitar uma segunda incisão cirúrgica com menor perda sanguínea durante a cirurgia, além de possibilitar reconstruções que requerem maior quantidade de enxerto. ${ }^{2-4}$

Na ortopedia, os enxertos ósseos são utilizados principalmente nas cirurgias de escoliose, ressecção de tumores musculoesqueléticos, no tratamento das pseudartroses, e nas revisões de artroplastias do quadril e joelho, que apresentam números crescentes de procedimentos. ${ }^{2,4} \mathrm{O}$ aprimoramento dos bancos de tecidos no preparo e oferta de diferentes tipos de enxertos proporcionaram progressos na eficácia dos transplantes ósseos e nas cirurgias de revisão de artroplastia com perda grave de estoque ósseo. ${ }^{5-7}$

Existe grande preocupação em garantir a qualidade dos tecidos ósseos e promover a segurança dos pacientes receptores em relação à transmissão de doenças infectocontagiosas. ${ }^{4}$

Somente o processo de esterilização por radiação ionizante dos tecidos promove nível de segurança de $10^{-6}$, ou seja, probabilidade de 1:1.000.000 de encontrar microorganismos viáveis, e este método apresenta vantagens com relação a outros métodos de esterilização, tais como: boa penetrabilidade, não deixa resíduos tóxicos, e pode ser utilizado como uma esterilização final, ou seja, evitando o risco de contaminação por manipulação após a esterilização. ${ }^{8} \mathrm{~A}$ aplicação da radiação gama com fontes de ${ }^{6^{\circ}} \mathrm{Co}$ na esterilização de tecidos biológicos tem sido utilizada há anos; porém, diversos autores demonstram que este procedimento pode acarretar alterações estruturais e biológicas, conforme a dose aplicada. ${ }^{9-11}$

O presente estudo avalia e compara a osteointegração dos enxertos ósseos congelados irradiados e não irradiados utilizados em pacientes submetidos a revisão de prótese do quadril.

\section{Materiais e Métodos}

Trata-se de um estudo retrospectivo com 21 pacientes submetidos a revisão de artroplastia do quadril pela técnica Exeter, com utilização de tecidos ósseos tratados ou não com radiação gama no período entre 2013 e 2014 . Um total de 14 pacientes eram do sexo masculino, e 7, do sexo feminino, com idade entre 48 e 85 anos (média de 67,7 anos). 0 estudo foi aprovado pelo Comitê de Ética, e foi realizado no banco de tecidos em conjunto com o grupo do quadril, ambos da nossa instituição.

As avaliações radiológicas de rotina no pré-operatório e pós-operatório imediato, e depois de 6 e 12 meses, foram realizadas para a interpretação da osteointegração dos enxertos, conforme podemos observar na - Figura 1.

Reunimos os critérios radiográficos propostos por Coon et $\mathrm{l}^{12}$ e Azuma et $\mathrm{al}^{13}$ para a interpretação da integração óssea durante o acompanhamento do pós-cirúrgico dos pacientes nos períodos de 6 e 12 meses, e estratificamos, conforme a - Tabela 1. 

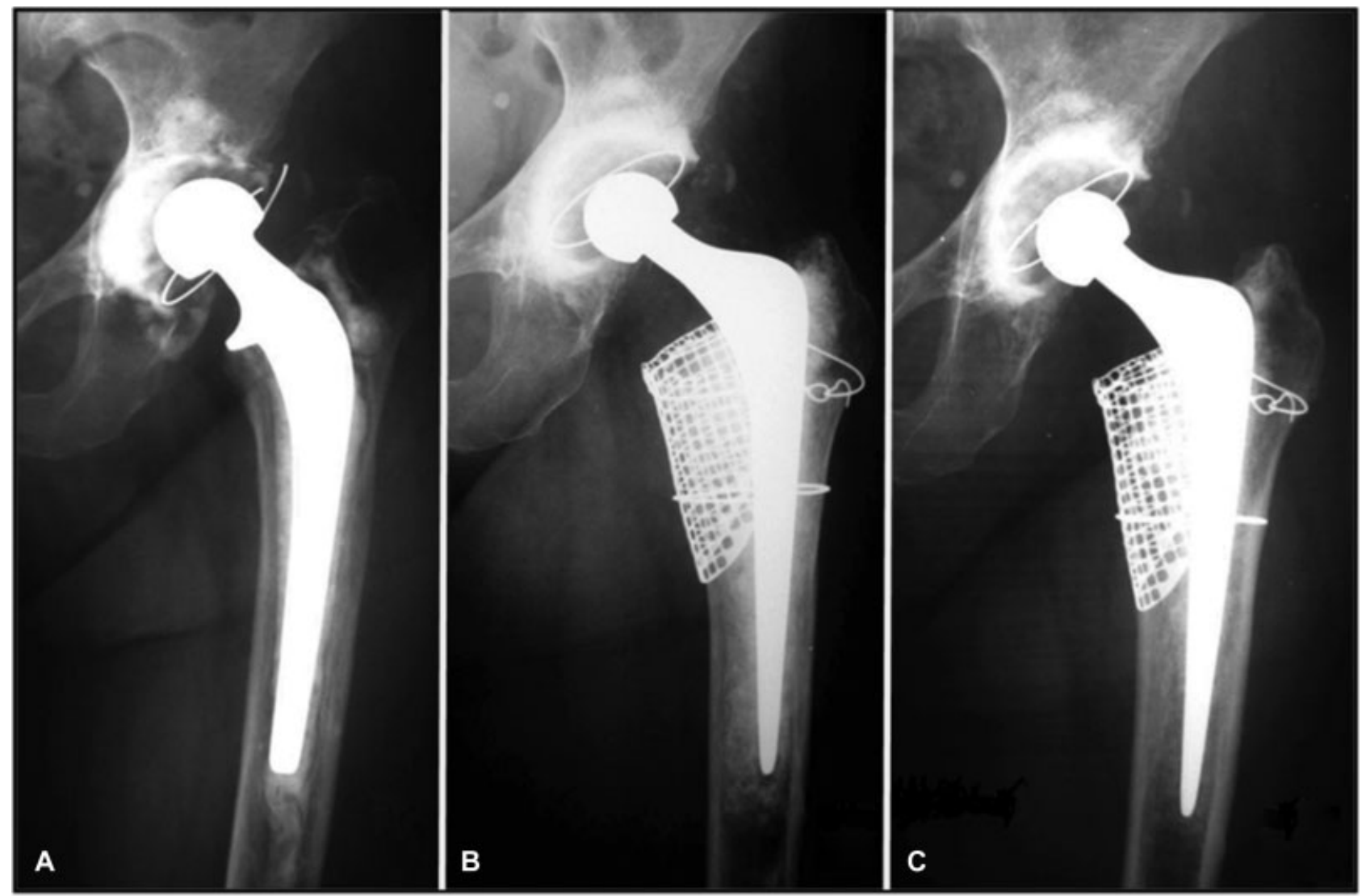

Fig. 1 Radiografias de incidência ântero-posterior do quadril esquerdo. (A) Radiografia pré-operatória com avaliação de perda óssea no acetábulo e fêmur esquerdo. (B) Radiografia do pós-cirúrgico imediato à cirurgia de revisão da prótese com o uso de enxerto ósseo irradiado no acetábulo e no fêmur. (C) Radiografia do pós-cirúrgico de 12 meses, em que se nota a integração óssea do enxerto irradiado ao acetábulo e ao fêmur.

Tabela 1 Classificação da integração óssea de enxerto impactado por técnica Exeter, conforme descrito por Coon et al ${ }^{12}$ e Azuma et al ${ }^{13}$

\begin{tabular}{|l|l|}
\hline $\begin{array}{l}\text { Classificação de } \\
\text { osteointegração }\end{array}$ & Condições propostas para a classificação de osteointegração \\
\hline $\begin{array}{l}\text { 1-Osteointegração } \\
\text { total do enxerto }\end{array}$ & $\begin{array}{l}\text { Formação total de molde trabecular contínuo na região de interface entre o enxerto ósseo e } \\
\text { o osso do receptor, denotando o aparecimento de novo padrão trabecular semelhante à } \\
\text { estrutura óssea normal em todas as áreas do enxerto impactado, seguida de reorganização } \\
\text { óssea, desaparecimento da linha esclerótica presente na interface enxerto-receptor, } \\
\text { e radiodensidade idêntica entre o enxerto e o osso do receptor. }\end{array}$ \\
\hline $\begin{array}{l}\text { 2-Osteointegração } \\
\text { parcial do enxerto }\end{array}$ & $\begin{array}{l}\text { Formação parcial de molde trabecular contínuo na região de interface entre o enxerto } \\
\text { ósseo e osso do receptor, denotando o aparecimento de novo padrão trabecular semelhante } \\
\text { à estrutura óssea normal parcialmente nas áreas do enxerto impactado, seguida de } \\
\text { reorganização óssea, desaparecimento parcial da linha esclerótica presente na interface } \\
\text { enxerto-receptor, e radiodensidade idêntica entre o enxerto e o osso do receptor. }\end{array}$ \\
\hline $\begin{array}{l}\text { 3-Ausência de } \\
\text { osteointegração }\end{array}$ & Não houve osteointegração do enxerto. \\
\hline $\begin{array}{l}\text { 4-Inviabilidade de avaliar } \\
\text { a osteointegração }\end{array}$ & $\begin{array}{l}\text { Impossibilidade de visualizar os enxertos devido à presença de tela ou outros } \\
\text { dispositivos protéticos. }\end{array}$ \\
\hline
\end{tabular}

Dividimos os pacientes em dois grupos, de acordo com o uso do enxerto tratado ou não com radiação ionizante (raios gama), e eles foram, portanto, classificados como: grupo irradiado e não irradiado.

Os tecidos foram irradiados por radiação gama na dose de $25 \mathrm{kGy}$, com taxa de dose de $0,00138 \mathrm{kGy} / \mathrm{s}$ e temperatura aproximada de $-70^{\circ} \mathrm{C}$, pois estas condições reduzem os efeitos indesejáveis da radiação, tais como: altas doses, alta taxa de transferência de energia e o aquecimento, respectivamente, com o intuito de manter a integridade das propriedades biológicas dos tecidos. ${ }^{4}$

Os resultados foram analisados e comparados entre os grupos estudados. Foram excluídos 3 pacientes durante a comparação dos grupos irradiados e não irradiados com classificação de osteointegração número 4. A análise estatística foi realizada por comparação dos resultados pelo teste 
de Mann-Whitney não pareado e não paramétrico para diferenças estastísticas $(p<0,05)$.

\section{Resultados}

Dos 21 pacientes estudados, 7 pertenciam ao grupo irradiado (uso de enxerto ósseo congelado irradiado), e 14, ao grupo não irradiado (uso de enxerto ósseo congelado não irradiado). Os diagnósticos iniciais dos pacientes que motivaram a artroplastia primária do quadril foram: artrose do quadril (71,4\%); fratura do colo femoral ou do acetábulo $(14,2 \%)$; necrose da cabeça femoral $(4,8 \%)$; displasia do desenvolvimento do quadril (4,8\%); e espondilite anquilosante $(4,8 \%)$. Nenhum dos casos avaliados apresentou infecção.

A quantidade em gramas de enxertos ósseos utilizados nos pacientes apresentou uma variação de 50 a 266 g (média de $128,4 \mathrm{~g})$.

$\mathrm{Na}$ - Tabela 2, podemos observar que 8 pacientes tiveram osteointegração parcial com avaliação radiográfica no pós-

Tabela 2 Registro das análises por radiografia da osteointegração dos enxertos ósseos transplantados nos grupos irradiados e não irradiados no pós-cirúrgico de 6 e 12 meses, pela técnica Exeter e de acordo com a classificação proposta

\begin{tabular}{|c|c|c|c|}
\hline \multirow[t]{2}{*}{ Grupos } & \multirow[t]{2}{*}{ Pacientes } & \multicolumn{2}{|c|}{$\begin{array}{l}\text { Classificação de } \\
\text { osteointegração }\end{array}$} \\
\hline & & $\begin{array}{l}6 \text { meses de } \\
\text { pós-cirúrgico }\end{array}$ & $\begin{array}{l}12 \text { meses de } \\
\text { pós-cirúrgico }\end{array}$ \\
\hline \multirow[t]{7}{*}{ Irradiado } & Paciente $n^{\circ} 1$ & 2 & 1 \\
\hline & Paciente $n^{\circ} 2$ & 3 & 2 \\
\hline & Paciente $n^{\circ} 3$ & 2 & 1 \\
\hline & Paciente $\mathrm{n}^{\circ} 4$ & 4 & 4 \\
\hline & Paciente $n^{\circ} 5$ & 3 & 3 \\
\hline & Paciente $n^{\circ} 6$ & 2 & 1 \\
\hline & Paciente $n^{\circ} 7$ & 3 & 3 \\
\hline \multirow{14}{*}{$\begin{array}{l}\text { Não } \\
\text { irradiado }\end{array}$} & Paciente $n^{\circ} 8$ & 3 & 3 \\
\hline & Paciente $n^{\circ} 9$ & 2 & 1 \\
\hline & Paciente $n^{\circ} 10$ & 2 & 1 \\
\hline & Paciente $n^{\circ} 11$ & 3 & 2 \\
\hline & Paciente $n^{\circ} 12$ & 2 & 1 \\
\hline & Paciente $n^{\circ} 13$ & 3 & 3 \\
\hline & Paciente $n^{\circ} 14$ & 2 & 1 \\
\hline & Paciente $n^{\circ} 15$ & 3 & 2 \\
\hline & Paciente $n^{\circ} 16$ & 3 & 2 \\
\hline & Paciente $n^{\circ} 17$ & 4 & 4 \\
\hline & Paciente $n^{\circ} 18$ & 3 & 3 \\
\hline & Paciente $n^{\circ} 19$ & 2 & 1 \\
\hline & Paciente $n^{\circ} 20$ & 4 & 4 \\
\hline & Paciente $n^{\circ} 21$ & 3 & 3 \\
\hline
\end{tabular}

Nota: Classificação da osteointegração: 1- Osteointegração total do enxerto; 2- Osteointegração parcial do enxerto; 3- Ausência de osteointegração; 4- Inviabilidade de avaliar a osteointegração. cirúrgico de 6 meses, e, após 12 meses, evoluíram para osteointegração total do enxerto, e 4 pacientes com avaliação de ausência de osteointegração no pós-cirúrgico de 6 meses apresentaram osteointegração parcial após 12 meses. No entanto, 6 pacientes não apresentaram osteointegração no pós-cirúrgico de 6 meses e 12 meses, e não foi possível avaliar 3 pacientes quanto à osteointegração devido à presença de tela ou de outros dispositivos protéticos. Houve diferença significativa entre as avaliações de 6 e 12 meses $(p=0,031)$.

Nas - Figuras 2 e 3, observamos a comparação do percentual de osteointegração entre os dois grupos. Não foram observadas diferenças estatisticamente significativas $(p=0.804)$.

\section{Discussão}

A técnica Exeter vem sendo aplicada no grupo do quadril da nossa instituição nas últimas décadas. Embora não seja o objetivo deste estudo, esta técnica foi bem descrita por Wilson et al, $^{14}$ que avaliaram 705 casos com alta taxa de efetividade (98,8\%).

Na resposta biológica que ocorre após o transplante ósseo nas revisões de artroplastia do quadril, espera-se primeiramente a ocorrência do evento de consolidação do enxerto, conforme relatado por Jasty e Harris. ${ }^{15} \mathrm{O}$ enxerto pode apenas se consolidar, e existem situações em que o enxerto consolidado pode se integrar ao osso hospedeiro. Portanto, consolidação e osteointegração são processos distintos. $\mathrm{Na}$ consolidação, temos a união do enxerto ao osso hospedeiro pela formação de osso entre estes, e na osteointegração ocorre a substituição do enxerto por tecido ósseo do receptor por eventos de reabsorção e recolonização celular, resultando em uma substituição progressiva de um por outro. ${ }^{16}$

O tempo do processo de osteointegração depende da estabilidade mecânica e da quantidade do enxerto utilizado, e, também, da resposta biológica do receptor. A osteointegração é de extrema importância para a restauração do estoque ósseo e para uma maior durabilidade da prótese. ${ }^{17}$

Foram realizadas avaliações retrospectivas pós-cirúrgicas em 21 pacientes submetidos a revisão de artroplastia do quadril pela técnica Exeter com o uso de enxerto irradiado e não irradiado. Os dados epidemiológicos dos pacientes, tais como idade, sexo, entre outros, são dados apenas descritivos, pois o nosso número de casos era insuficiente para que se fizesse uma análise estatística nessa amostra. Entretanto, Böhm e Bischel ${ }^{18}$ afirmaram que não houve diferença na integração dos enxertos quando foram comparados idade, o sexo, o peso corporal, e o diagnóstico, entre outros critérios.

Existe uma intensa preocupação em garantir a qualidade dos tecidos e promover a segurança dos pacientes receptores de tecidos homólogos com relação à transmissão de doenças infectocontagiosas. Com o propósito de diminuir possíveis contaminações, são realizados, no doador de tecidos ósseos, triagem sorológica, avaliação do histórico e comportamento social, assim como testes de biologia molecular para detecção de RNA viral de vírus da imunodeficiência humana (HIV) e de vírus da hepartite $\mathrm{C}(\mathrm{HCV})$, exames clínicos e controles microbiológicos, além de serem aplicadas técnicas assépticas 


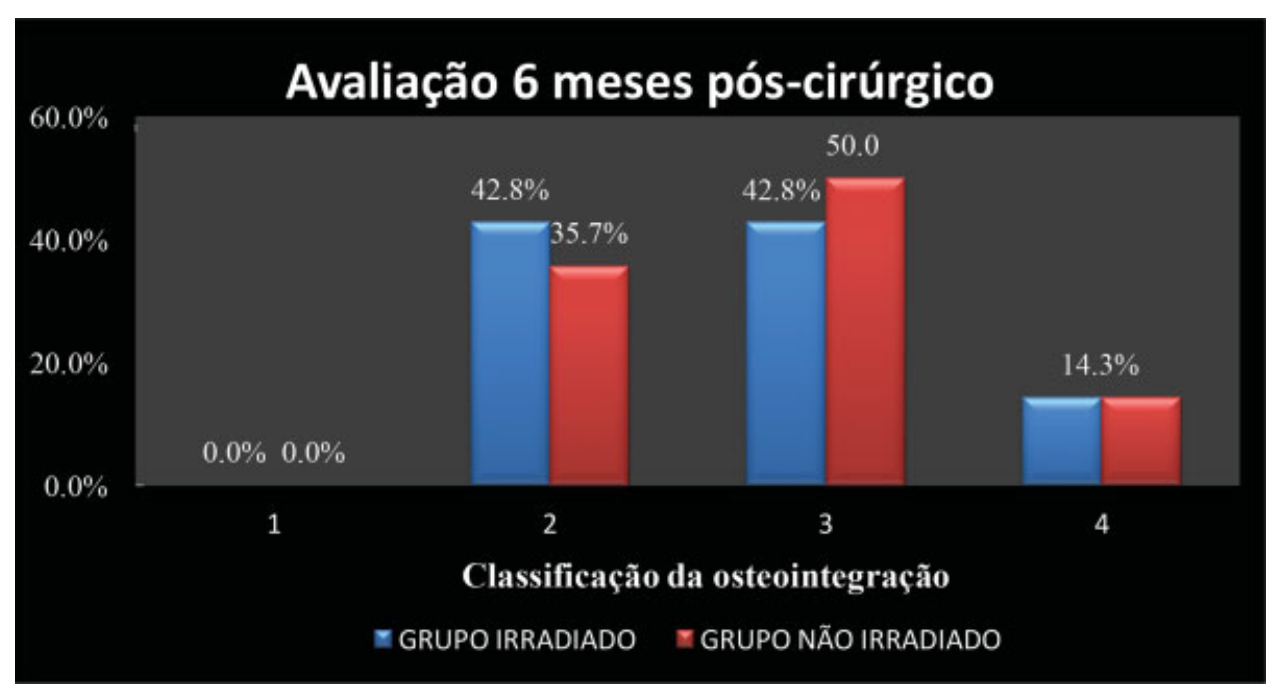

Fig. 2 Comparação do percentual da osteointegração dos grupos estudados no pós-cirúrgico de seis meses dos pacientes submetidos a revisão de artroplastia do quadril com enxertia óssea pela técnica Exeter. Classificação da osteointegração: 1- Osteointegração total do enxerto; 2- Osteointegração parcial do enxerto; 3- Ausência de osteointegração; 4- Inviabilidade de avaliar a osteointegração.

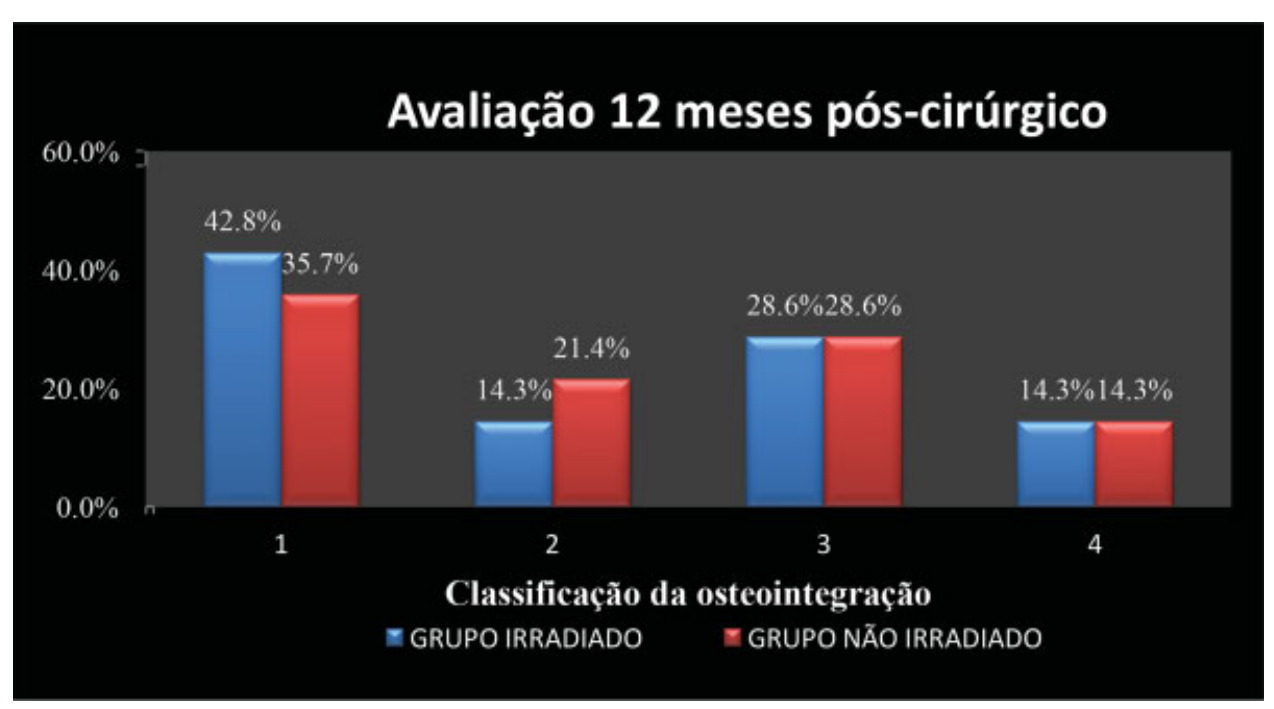

Fig. 3 Comparação do percentual da osteointegração dos grupos estudados no pós-cirúrgico de12 meses dos pacientes submetidos à revisão de artroplastia do quadril com enxertia óssea pela técnica Exeter. Classificação da osteointegração: 1-Osteointegração total do enxerto; 2- Osteointegração parcial do enxerto; 3- Ausência de osteointegração; 4- Inviabilidade de avaliar a osteointegração.

durante os procedimentos. ${ }^{10}$ Entretanto, existe a possibilidade de contaminação por microorganismos durante a captação, o processamento, a preservação e o armazenamento dos tecidos. ${ }^{19}$

A segurança microbiológica dos tecidos musculoesqueléticos pode ser aumentada com o emprego da esterilização dos enxertos.

A radiação gama é a mais utilizada nos bancos de tecidos, e é um método eficaz para proporcionar a esterilização terminal do tecido biológico; porém, há relatos sobre os possíveis efeitos deletérios das propriedades mecânicas e biológicas dos tecidos, dependendo da dose de radiação aplicada. ${ }^{10}$ Por este motivo, usualmente são aplicadas doses menores de radiação, entre $15 \mathrm{kGy}$ a $25 \mathrm{kGy}$, e, com menor frequência, doses mais altas ( $>25 \mathrm{kGy}$ ).
A análise da osteointegração por exame radiográfico de acompanhamento foi proposta por Conn et al, ${ }^{12}$ que consideraram o enxerto integrado quando a radiodensidade entre o enxerto e o osso receptor era idêntica, com formação de um molde trabecular contínuo na interface enxerto-receptor, denotando um novo padrão trabecular, segundo as cargas que foram aplicadas nesta região, ocorrendo então uma reorganização óssea. Posteriormente, Azuma et al ${ }^{13}$ consideraram o enxerto incorporado quando a linha esclerótica presente na interface enxerto-receptor desaparecia, com restauração da densidade normal do enxerto. 0 nosso grupo decidiu associar estas definições para avaliar melhor a integração óssea. Contudo, esta análise por avaliação radiográfica pode ser subjetiva e de difícil interpretação, principalmente na presença de material de síntese, como 
telas metálicas, anel de reforço acetabular, e parafusos, entre outros.

A melhor técnica de comprovação da osteointegração é o estudo histológico do enxerto transplantado; entretanto, esta técnica não é realizada rotineiramente, principalmente por ser invasiva. ${ }^{20}$ Comparando a avaliação da osteointegração no período de 6 meses com o de 12 meses após o transplante, os resultados indicam diferenças significativas $(p=0,031)$, o que pode ser explicado por maiores evidências radiológicas de osteointegração na avaliação de 12 meses.

Quando comparamos a osteointegração dos grupos que utilizaram enxertos irradiados e não irradiados em nosso estudo, não observamos diferenças estatisticamente significativas; porém, sugerimos mais estudos para afirmar que o uso de ossos irradiados com doses controladas de radiação gama (25 kGy) é tão eficaz nas reconstruções ósseas realizadas nas revisões de artroplastias do quadril quanto o uso dos enxertos não irradiados. Estes resultados também foram descritos por Emms et al, ${ }^{21}$ que estudaram o uso de enxerto irradiado em reconstruções acetabulares em médio e longo período de tempo (de 2 e 12 anos) em 110 pacientes que relataram bons resultados no acompanhamento pós-cirúrgico, resultados comparáveis ao uso de enxertos não irradiados.

\section{Conclusão}

Não houve diferença significativa no uso de enxerto irradiado e não irradiado nas revisões de artroplastias do quadril pela técnica Exeter.

\section{Conflitos de Interesse}

Os autores declaram não haver conflitos de interesse.

\section{Referências}

1 Associação Brasileira de Transplantes de Órgãos (ABTO). Registro Brasileiro de Transplantes. Ano XXII n. 4, jan/fev 2016. Disponível em: http://www.abto.org.br/abtov03/default.aspx?mn=457\&c= 900\&s $=0$

2 Halliday BR, English HW, Timperley AJ, Gie GA, Ling RS. Femoral impaction grafting with cement in revision total hip replacement. Evolution of the technique and results. J Bone Joint Surg Br 2003; 85(06):809-817

3 Zabeu JL, Mercadante MT. Substitutos ósseos comparados ao enxerto ósseo autólogo em cirurgia ortopédica. Revisão sistemática da literatura. Rev Bras Ortop 2008;43(03):59-68

4 Antebi U, Mathor MB, Silva AF, Guimarães RP, Honda EK. Efeitos da radiação ionizante nas proteínas presentes em ossos humanos desmineralizados, liofilizados ou congelados. Rev Bras Ortop 2016;51(02):224-230

5 Sutherland CJ, Wilde AH, Borden LS, Marks KE. A ten-year follow-up of one hundred consecutive Müller curved-stem total hip-replacement arthroplasties. J Bone Joint Surg Am 1982;64(07):970-982

6 Friedlaender GE, Goldberg VM. Bone and cartilage allografts: biology and clinical applications. Illinois: American Academy of Orthopedic Surgeons; 1991

7 Graham NM, Stockley I. The use of structural proximal femoral allografts in complex revision hip arthroplasty. J Bone Joint Surg Br 2004;86(03):337-343

8 Dziedzic-Goclawska A. The application of ionising radiation to sterilise connective tissue allografts. In: Phillips GO. Radiation and tissue banking. World ScientificSingapore2000:57-99

9 Vastel L, Masse C, Crozier E, et al. Effects of gamma irradiation on mechanical properties of defatted trabecular bone allografts assessed by speed-of-sound measurement. Cell Tissue Bank 2007;8(03):205-210

10 Nguyen H, Morgan DA, Forwood MR. Sterilization of allograft bone: effects of gamma irradiation on allograft biology and biomechanics. Cell Tissue Bank 2007;8(02):93-105

11 Pekkarinen T, Hietalal O, Jämsä T, Jalovaara P. Gamma irradiation and ethylene oxide in the sterilization of native reindeer bone morphogenetic protein extract. Scand J Surg 2005;94(01):67-70

12 Conn RA, Peterson LF, Stauffer RN, Listrup D. Management of acetabular deficiency: long term results of bone grafting the acetabulum in total hip arthroplasty. Trans Orthop Res Soc 1985; 9:451-452

13 Azuma T, Yasuda H, Okagaki K, Sakai K. Compressed allograft chips for acetabular reconstruction in revision hip arthroplasty. J Bone Joint Surg Br 1994;76(05):740-744

14 Wilson MJ, Hook S, Whitehouse SL, Timperley AJ, Gie GA. Femoral impaction bone grafting in revision hip arthroplasty: 705 cases from the originating centre. Bone Joint J 2016;98-B(12):1611-1619

15 Jasty M, Harris WH. Salvage total hip reconstruction in patients with major acetabular bone deficiency using structural femoral head allografts. J Bone Joint Surg Br 1990;72(01):63-67

16 Galia CR, Moreira LF. The Biology of Bone Grafts: Recent Advances in Arthroplasty, 2012. Samo K. Fokter, IntechOpen, InTech; 235-254. DOI: $10.5772 / 27381$.

17 Schreurs BW, Slooff TJ, Gardeniers JW, Buma P. Acetabular reconstruction with bone impaction grafting and a cemented cup: 20 years' experience. Clin Orthop Relat Res 2001;(393):202-215

18 Böhm P, Bischel O. The use of tapered stems for femoral revision surgery. Clin Orthop Relat Res 2004;(420):148-159

19 Phillips GO. Module 5: Processing. In: Multimedia distance learning package on tissue banking. Singapura: IAEA; 1997

20 Devito FS, Aristides RS, Honda EK, Chueire AG. O uso de enxerto homólogo na revisão de artroplastias do quadril com cimentação do componente acetabular. Acta Ortop Bras 2006;14(05):280-282

21 Emms NW, Buckley SC, Stockley I, Hamer AJ, Kerry RM. Mid- to longterm results of irradiated allograft in acetabular reconstruction: a follow-up report. J Bone Joint Surg Br 2009;91(11):1419-1423 